\title{
Effects of ecological factors on secondary metabolites and inorganic elements of Scutellaria baicalensis and analysis of geoherblism
}

\author{
GUO LanPing $^{1 \dagger}$, WANG Sheng ${ }^{1 \dagger}$, ZHANG Ji $^{2}$, YANG Guang ${ }^{1}$, ZHAO ManXi $^{1}$, \\ MA WeiFeng ${ }^{1}$, ZHANG XiaoBo $^{1}$, LI Xuan ${ }^{1}$, HAN BangXing ${ }^{3}$, CHEN NaiFu $^{3}$ \& HUANG LuQi ${ }^{*}$ \\ ${ }^{1}$ National Resources Center of Chinese Material Medica, China Academy of Chinese Medical Sciences, Beijing 100700, China; \\ ${ }^{2}$ Medicinal Plant Institute, Yunnan Academy of Agricultural Sciences, Kunming 650223, China; \\ ${ }^{3}$ School of Biological and Pharmaceutical Engineering, West Anhui University, Lu'an 237012, China
}

Received July 29, 2013; accepted September 5, 2013

\begin{abstract}
This study analyzed the effects of ecological factors on secondary metabolites of Scutellaria baicalensis using two sources: 92 individual roots of $S$. baicalensis from all over China, and secondary metabolites, medicinal materials and inorganic element contents obtained from the testing of 92 S. baicalensis rhizosphere soil samples. The study used environmental data from the Genuine Medicinal Material Spatial Analysis Database. Most of the chemical constituents of S. baicalensis were negatively correlated to latitude and positively correlated to temperature; generally, the contents of 21 chemical constituents were higher at low latitudes than that at high latitudes. By gradual regression analysis, it was found that the content of baicalin in $S$. baicalensis was negatively correlated to latitude and generally the content of inorganic elements in soil was excessively high (excluding $\mathrm{Mg}$ and $\mathrm{Ca}$ ), which has a negative effect on the accumulation of chemical constituents in S. baicalensis. Based on the cluster analysis of 21 constituents, S. baicalensis from different places of origin was divided into two groups, and $S$. baicalensis was not genuine only in a specific small region. Within the zone from Chifeng, Inner Mongolia to Taibai, Shaanxi is suitable for accumulation of secondary metabolites of S. baicalensis and such a zone represents a suitable distribution and potential genuine producing area.
\end{abstract}

Scutellaria baicalensis, ecological factors, geoherbs, Daodi-herbs, geographical variation

Citation: Guo L P, Wang S, Zhang J, et al. Effects of ecological factors on secondary metabolites and inorganic elements of Scutellaria baicalensis and analysis of geoherblism. Sci China Life Sci, 2013, 56: 1047-1056, doi: 10.1007/s11427-013-4562-5

Some traditional Chinese medicines that are grown in specific regions and widely recognized as having better beneficial clinical therapeutic effects are called Daodi-herbs or geoherbs [1,2]. From a biological point of view, heterogeneous individuals of the same species can be classified as either geoherbs or non-geoherbs [3], with their unique chemical constituents resulting from the interaction between minor-polygenes and differential ecology [4]. Plants resist

$\dagger$ Contributed equally to this work

*Corresponding author (email: huangluqi@263.net) biological, physical and chemical environmental stresses by regulating the accumulation of secondary metabolites in long periods of adaption to the environment [5-9]. Ecological factors are the dominant factors affecting the secondary metabolites of the plants [10]. Therefore, research on the effects of ecological factors on the accumulation of secondary metabolites in medicinal plants is crucial for revealing the causes of geoherblism of traditional Chinese medicine, which is also a key for carrying out directional cultivation and improving the quality of traditional Chinese medicine. 
Huáng qín (Chinese: 黄芩) is originally from Scutellaria baicalensis. Its dried root is popular in traditional Chinese medicine. It works as an anti-inflammatory, antioxidant, and anti-allergen, and it is often used to treat fevers, coughs, allergic rhinitis, and wheezing [11]. Scutellaria baicalensis is widely distributed in Northeast China, North China, Central China and Southwest China, and is common in extensive areas north of the Yangtze River [12]. Research has demonstrated that variation in the quality of $S$. baicalensis is mainly due to environmental factors [13]. In our earlier study, 92 individual roots of $S$. baicalensis and the 92 corresponding rhizosphere soil samples were taken from all over China; the secondary metabolites in roots of S. baicalensis and inorganic elements in roots and rhizosphere soil were tested. Based on the data of these secondary metabolites and inorganic elements, massive environmental data from the Spatial Analysis Database of Geoherbs are used to investigate the influence of ecological factors on the accumulation of secondary metabolites and their comprehensive effect, which may provide guidance for high-quality cultivation of $S$. baicalensis.

\section{Sample plots and data sources}

\subsection{Sample plots}

To eliminate the effect of anthropogenic interference, all materials of $S$. baicalensis used in this study were taken from the wild. From the end of July 2007 to the beginning of September 2007, these samples were taken randomly from 16 main producing areas, from each of which 4-6 individual plants of $S$. baicalensis were collected to make a total of 92 plants. The information about the samples and their growing areas is given in Table 1.

\subsection{Data source}

Data regarding secondary metabolites of S. baicalensis: a total of 19 peaks and 21 constituents were tested in an HPLC chromatogram of S. baicalensis (constituents 4-6 were not completely separated and the three constituents come to one peak, so the total number of peaks was 19). The actual contents of the four constituents C9 baicalin, C14 wogonoside, C17 baicalein and C18 wogonin, were quantified from standard substances, while the contents of the rest of the constituents were indicated as peak areas in this study because of the absence of standard substances. The results indicated that the difference in the peak area of 21 constituents is significant among all the aforementioned areas (average peak areas of 19 peaks: 31264.05, 30113.50, 318188.06, 273922.13, 60614.93, 100584.08, 3622943.69, 260674.38, 74292.66, 129634.91, 353354.49, 922312.94, 46522.56, 24492.74, 614868.38, 198518.55, 30584.19, 10694.69 and 11552.00), suggesting that geographical en-

Table 1 S. baicalensis samples and information about their growing areas

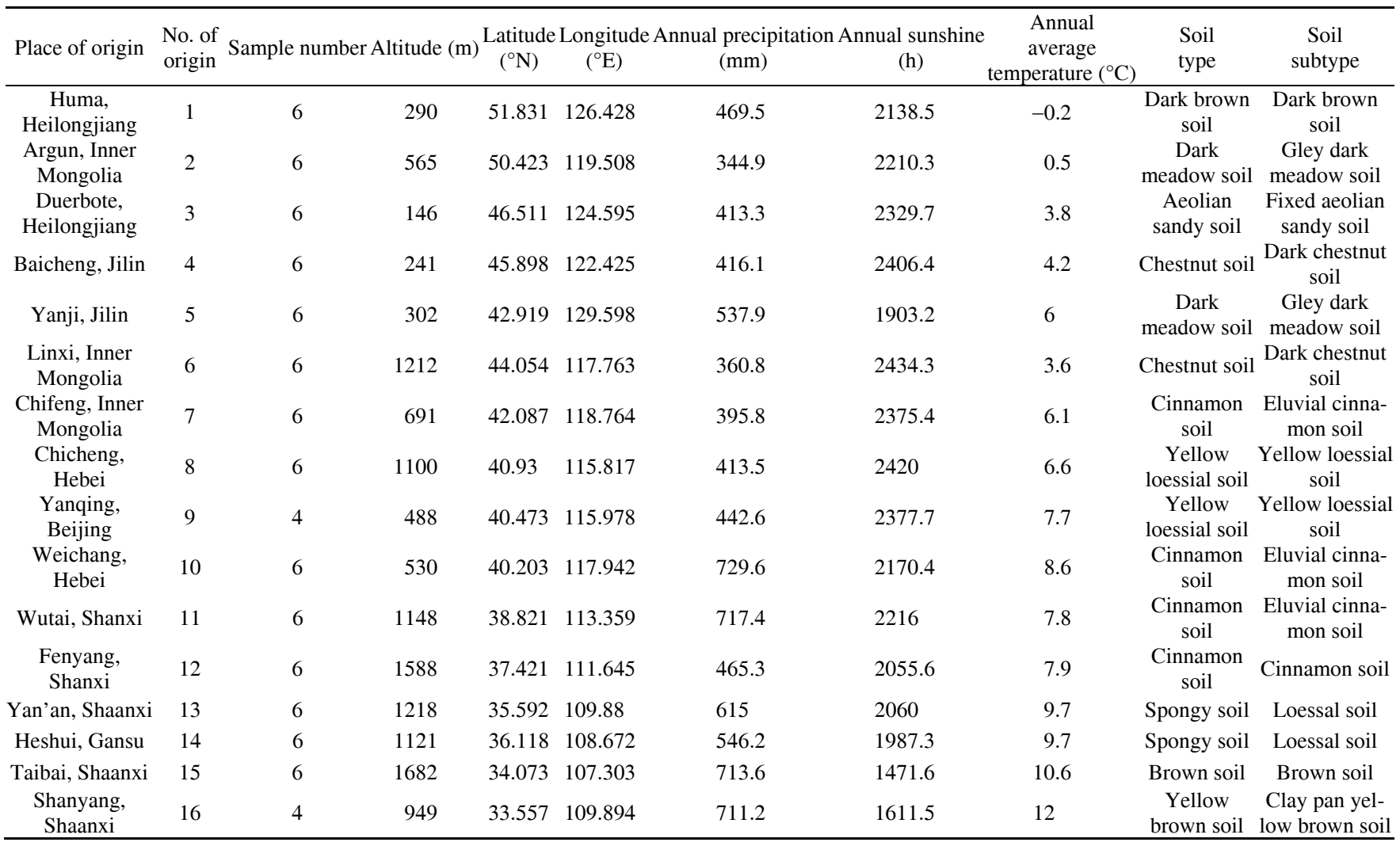


vironment has an impact on the contents of the chemical constituents of S. baicalensis.

Data regarding inorganic elements in S. baicalensis and their rhizosphere soil: the average contents of such inorganic elements as $\mathrm{Ca}, \mathrm{Cr}, \mathrm{Cu}, \mathrm{Fe}, \mathrm{K}, \mathrm{Mg}, \mathrm{Mn}, \mathrm{P}, \mathrm{Sr}$ and $\mathrm{Zn}$ in $\mathrm{S}$. baicalensis were 9891.85, 12.54, 23.09, 2150.84, 6336.77, $5736.96,70.83,692.09,74.4$ and $28.98 \mathrm{mg} \mathrm{kg}^{-1}$, respectively, and the average contents in rhizosphere soil were 37235.21, 209.41, 37.14, 14612.92, 22363.33, 9890.42, 908.89, 739.04, 40.91 and $70.54 \mathrm{mg} \mathrm{kg}^{-1}$, respectively. The contents of inorganic elements in S. baicalensis and rhizosphere soil were significantly different among all the aforementioned places, which suggest that the geographical environment may have an impact over the accumulation of inorganic elements in medicinal materials and the contents of inorganic elements in the soil may directly affect the accumulation of inorganic elements in the medicinal materials.

Data on meteorological factors: these data were sourced from the local meteorological station nearest to the sample plot and include the temperatures, annual precipitations, annual sunshine hours, and annual relative humidity over 30 years from 1971 to 2000 . A spatial interpolation analysis was performed on the averages of the dominant climate factors over the 30 years from 1971 to 2000 by using Surfer 7.0 and the Kriging method at an interpolation accuracy of $4 \mathrm{~km} \times 4 \mathrm{~km}$ to obtain the countrywide spatial distribution map for each dominating climate factor. An allowance of 1/5 magnitude was made for verifying the accuracy of the interpolation results $[14,15]$.

\section{Data processing}

The test results were analyzed with Excel 2003 and SPSS 13.0. Correlation analyses were conducted using Pearson coefficient test. Multiple comparisons were carried out using the SNK method. A multivariate regression analysis was conducted to establish the correlation model between environmental factors and chemical constituents. Cluster analysis showed the similarity of the chemical constituents of medicinal materials from different places of origin.

\section{Results and analyses}

\subsection{Correlation between ecological factors and sec- ondary metabolites of $S$. baicalensis}

\subsubsection{Correlation between climatic factors and secondary metabolites of $S$. baicalensis}

Usually latitude and longitude indirectly affect medicinal plants through the influence of temperature and precipitation, and their effect on plants is as important as temperature, precipitation, sunshine and other climatic factors. As seen from Table 2, among the 19 peaks, 11 components have no significant correlation with ecological factors, while the other eight components have significant correlation with up to six ecological factors. For example, component 9, which has the largest content, is significantly correlated with six ecological factors, and so are components 4-6 (which have not been separated). This suggests that different chemical compositions are influenced differently by ecological factors. Six ecological factors are significantly correlated with 3-7 chemical compositions, suggesting that the same ecological factors will have different influences on different chemical compositions. Among them, latitude and longitude are significantly correlated with seven and six chemical compositions respectively, suggesting that these two factors have the largest influence on chemical composition. Meanwhile, latitude and most chemical compositions are negatively correlated, while temperature and most chemical compositions are positively correlated, suggesting that high temperature is good for accumulation of the majority of chemical constituents inside the root of S. baicalensis. Studies of Zobayed et al. [16] have shown that heat stress is an important environmental factor in promoting accumulation of secondary metabolites for Hypericum (Hypericum perforatum).

Climatic and geographical differences will affect the composition and ratio [17] of flavonoid content inside plants. Stepwise regression analysis obtained the regression equation for baicalin and climatic factor: $Y_{\text {baicalin }}=$ 24.928-0.312 latitude $(F=18.054, P=0.000)$, which also showed that baicalin content is negatively correlated with latitude. The other three components, wogonoside, baicalei and wogonin, did not obtain the stepwise regression equation. The regression equation between baicalin and climatic factors could be obtained through the use of regression analysis: $\quad Y_{\text {baicalin }}=30.661-0.002$ altitude-0.364 latitude0.067 longitude-0.002 annual precipitation-0.001 annual sunshine duration-0.470 annual average temperature $(F=4.213, \quad P=0.001)$. The regression equation between wogonin and climatic factors was $Y_{\text {wogonin }}=0.193+0.018$ latitude-0.002 longitude-0.001 annual precipitation +0.042 annual average temperature $(F=3.061, P=0.009)$. No regression equation was obtained for wogonoside.

\subsubsection{Correlation between soil inorganic elements and secondary metabolites of $S$. baicalensis}

Table 3 shows 21 components in $S$. baicalensis with different correlations with 10 inorganic elements. Seven components have no significant correlation with inorganic elements, while the other components have significant correlation with 1-7 components. Among them, component 9, baicalin, and component 13 have significant correlation with seven kinds of inorganic elements, suggesting that each component is influenced differently by inorganic elements. Ten inorganic elements have significant correlation with 1-7 chemical compositions, $\mathrm{Mg}$ and $\mathrm{Mn}$ have signifi- 
Table 2 Correlation between 21 component contents (peak area) and ecological factors of S. baicalensis $^{\mathrm{a})}$

\begin{tabular}{|c|c|c|c|c|c|c|c|}
\hline & Ecological factor & Altitude (m) & Latitude $\left({ }^{\circ} \mathrm{N}\right)$ & Longitude $\left({ }^{\circ} \mathrm{E}\right)$ & $\begin{array}{c}\text { Annual precipitation } \\
(\mathrm{mm})\end{array}$ & $\begin{array}{c}\text { Annual sunshine } \\
\text { duration }(\mathrm{h})\end{array}$ & $\begin{array}{l}\text { Annual average } \\
\text { temperature }\left({ }^{\circ} \mathrm{C}\right)\end{array}$ \\
\hline Component & $\begin{array}{l}\text { Significant correla- } \\
\text { tion number }\end{array}$ & 3 & 7 & 4 & 5 & 5 & 6 \\
\hline C 1 & 0 & -0.209 & -0.160 & -0.036 & 0.116 & 0.124 & 0.253 \\
\hline $\mathrm{C} 2$ & 1 & 0.271 & -0.460 & $-0.556^{*}$ & 0.326 & -0.096 & 0.474 \\
\hline C 3 & 3 & 0.291 & $-0.517^{*}$ & $-0.630^{* *}$ & 0.395 & -0.454 & $0.512^{*}$ \\
\hline C 4-6 & 6 & $0.565^{*}$ & $-0.729^{* *}$ & $-0.707^{* *}$ & $0.749^{* *}$ & $-0.594^{*}$ & $0.715^{* *}$ \\
\hline C 7 & 4 & $-0.567^{*}$ & $0.669^{* *}$ & 0.459 & $-0.521^{*}$ & 0.454 & $-0.642^{* *}$ \\
\hline $\mathrm{C} 8$ & 0 & 0.079 & -0.122 & -0.228 & -0.202 & 0.005 & 0.103 \\
\hline $\mathrm{C} 9$ & 6 & $0.569^{*}$ & $-0.614^{*}$ & $-0.599^{*}$ & $0.509^{*}$ & $-0.506^{*}$ & $0.559^{*}$ \\
\hline C 10 & 3 & 0.461 & $-0.506^{*}$ & -0.401 & $0.531^{*}$ & $-0.627^{* *}$ & 0.465 \\
\hline C 11 & 3 & 0.468 & $-0.554^{*}$ & -0.470 & 0.480 & $-0.781^{* *}$ & $0.507^{*}$ \\
\hline C 12 & 0 & 0.215 & -0.234 & 0.043 & 0.386 & -0.221 & 0.214 \\
\hline C 13 & 0 & 0.423 & -0.091 & -0.288 & 0.187 & -0.429 & -0.014 \\
\hline C 14 & 0 & 0.380 & -0.330 & -0.227 & 0.299 & -0.345 & 0.297 \\
\hline C 15 & 0 & -0.155 & -0.033 & -0.099 & -0.242 & 0.172 & 0.066 \\
\hline C 16 & 0 & -0.167 & -0.092 & -0.141 & -0.171 & 0.011 & 0.128 \\
\hline C 17 & 0 & -0.079 & -0.188 & -0.200 & -0.097 & -0.150 & 0.212 \\
\hline C 18 & 0 & -0.432 & 0.147 & 0.239 & -0.324 & 0.082 & -0.073 \\
\hline C 19 & 0 & -0.186 & -0.013 & 0.060 & -0.080 & -0.204 & 0.060 \\
\hline C 20 & 4 & -0.485 & $0.654^{* * *}$ & 0.383 & $-0.558^{*}$ & $0.540^{*}$ & $-0.639^{* *}$ \\
\hline C 21 & 0 & -0.264 & 0.112 & -0.006 & -0.354 & 0.118 & -0.068 \\
\hline
\end{tabular}

a) * shows significance at the level as $\alpha=0.05$; ** shows significance at the level as $\alpha=0.01$; C9 as baicalin, $\mathrm{C} 14$ as wogonoside, $\mathrm{C} 17$ as baicalein, $\mathrm{C} 18$ as wogonin.

Table 3 Relevant analysis between 21 component contents (peak area) and soil inorganic elements of S. baicalensis ${ }^{\mathrm{a})}$

\begin{tabular}{|c|c|c|c|c|c|c|c|c|c|c|c|}
\hline & Element & $\mathrm{Ca}$ & $\mathrm{Cr}$ & $\mathrm{Cu}$ & $\mathrm{Fe}$ & $\mathrm{K}$ & $\mathrm{Mg}$ & $\mathrm{Mn}$ & $P$ & $\mathrm{Sr}$ & $\mathrm{Zn}$ \\
\hline Component & $\begin{array}{c}\text { Significant } \\
\text { correlation number }\end{array}$ & 2 & 6 & 5 & 6 & 4 & 7 & 7 & 1 & 5 & 1 \\
\hline C 1 & 2 & -0.023 & 0.202 & 0.187 & 0.204 & 0.071 & 0.001 & $0.230^{*}$ & 0.020 & $0.239^{*}$ & -0.018 \\
\hline $\mathrm{C} 2$ & 0 & 0.191 & 0.151 & 0.104 & 0.123 & 0.009 & 0.077 & 0.044 & -0.090 & 0.095 & -0.100 \\
\hline C 3 & 5 & 0.197 & $-0.245^{*}$ & -0.205 & $-0.251^{*}$ & $-0.341^{* *}$ & 0.176 & $-0.260^{*}$ & 0.033 & $-0.228^{*}$ & 0.079 \\
\hline C 4-6 & 1 & 0.161 & 0.018 & 0.011 & -0.041 & -0.152 & $0.434^{* *}$ & -0.006 & -0.078 & 0.025 & 0.126 \\
\hline $\mathrm{C} 7$ & 6 & -0.050 & $-0.306^{* *}$ & $-0.387^{* * *}$ & $-0.305^{* *}$ & -0.083 & $-0.465^{* *}$ & $-0.234^{*}$ & $0.293^{* *}$ & -0.155 & -0.051 \\
\hline C 8 & 5 & -0.170 & $-0.316^{* * *}$ & $-0.253^{*}$ & $-0.296^{* *}$ & -0.182 & 0.076 & $-0.300^{* *}$ & 0.010 & $-0.349^{* *}$ & 0.139 \\
\hline C 9 & 7 & $0.222^{*}$ & $-0.210^{*}$ & $-0.213^{*}$ & $-0.278^{* *}$ & $-0.258^{*}$ & $0.271^{* *}$ & $-0.283^{* *}$ & -0.168 & -0.188 & -0.048 \\
\hline C 10 & 1 & 0.035 & -0.100 & -0.099 & -0.136 & -0.094 & $0.343^{* *}$ & -0.084 & 0.036 & -0.106 & 0.192 \\
\hline C 11 & 6 & $0.215^{*}$ & $-0.265^{*}$ & -0.156 & $-0.277^{* *}$ & $-0.273^{* *}$ & 0.176 & $-0.284^{* *}$ & -0.126 & $-0.280^{* * *}$ & -0.005 \\
\hline C 12 & 0 & -0.061 & 0.023 & -0.024 & 0.013 & 0.059 & 0.077 & 0.024 & 0.004 & 0.054 & 0.075 \\
\hline C 13 & 7 & 0.107 & $-0.291^{* * *}$ & $-0.258^{*}$ & $-0.300^{* *}$ & $-0.299^{* *}$ & 0.137 & $-0.283^{* * *}$ & 0.123 & $-0.304^{* * *}$ & $0.229^{*}$ \\
\hline C 15 & 0 & -0.129 & -0.066 & -0.044 & -0.038 & -0.062 & -0.084 & -0.056 & 0.073 & -0.125 & 0.127 \\
\hline C 16 & 0 & 0.024 & -0.134 & -0.103 & -0.135 & -0.119 & -0.186 & -0.174 & -0.071 & -0.193 & -0.003 \\
\hline C 17 & 0 & 0.184 & -0.141 & -0.083 & -0.130 & -0.165 & -0.197 & -0.196 & -0.084 & -0.193 & -0.079 \\
\hline C 18 & 1 & 0.000 & 0.017 & 0.054 & 0.065 & 0.004 & $-0.271^{* *}$ & -0.002 & -0.021 & -0.022 & -0.059 \\
\hline C 19 & 0 & 0.081 & 0.122 & 0.201 & 0.159 & 0.051 & -0.189 & 0.074 & -0.093 & 0.017 & -0.025 \\
\hline C 20 & 2 & -0.173 & -0.126 & $-0.209^{*}$ & -0.112 & 0.104 & $-0.320^{* *}$ & -0.027 & 0.132 & -0.048 & 0.038 \\
\hline C 21 & 0 & -0.024 & -0.040 & -0.021 & -0.019 & 0.054 & -0.170 & -0.065 & -0.059 & -0.058 & -0.036 \\
\hline
\end{tabular}

a) * shows significance at the level as $\alpha=0.05$; ** shows significance at the level as $\alpha=0.01$; C9 as baicalin, $\mathrm{C} 14$ as wogonoside, $\mathrm{C} 17$ as baicalein, $\mathrm{C} 18$ as wogonin.

cant correlation with seven components, while $\mathrm{Cr}$ and $\mathrm{Fe}$ have significant correlation with six components, suggest- ing that these inorganic elements have larger influence on chemical composition. There are 44 significant correlations 
between chemical composition and inorganic elements, of which 34 are negative and 10 are positive. Of the 10 positive correlations, four different components are positively correlated with $\mathrm{Mg}$ (another three components are negatively correlated with $\mathrm{Mg}$ ), and $\mathrm{Ca}$ has significant positive correlation with two chemical compositions, suggesting that many other inorganic elements with higher content are generally not conducive for the accumulation of chemical constituents inside $S$. baicalensis.

3.1.3 Correlation between inorganic elements and secondary metabolites of $S$. baicalensis

In the processes of growth, development and response to environmental stress in plants, inorganic element changes are significantly correlated [18] with changes in metabolites inside the body. Inorganic elements of S. baicalensis are in vivo ecological factors of secondary metabolite accumulation, and have important influence on secondary metabolites of $S$. baicalensis by ecological factors. As shown in Table 4, different chemical compositions of $S$. baicalensis have different correlations with inorganic elements. Six of the 21 components have no significant correlation with inorganic elements, while the other components have significant correlations with 1-7 kinds of inorganic elements. Component 9 (baicalin) has significant correlations with seven inorganic elements of medicinal material; component 10 has significant correlations with six inorganic elements of medicinal material. Ten inorganic elements inside S. baicalensis are significantly correlated with 3-6 chemical compositions, and six inorganic elements have significant correlations with five different chemical compositions. This shows that the frequency of significant correlations between different chemical compositions and inorganic elements is very low, while the frequency of significant correlations between inorganic elements and chemical compositions is very high.

\subsection{Correlation between ecological factors and inor- ganic elements of $S$. baicalensis}

\subsubsection{Correlation among inorganic elements of S. bai- calensis}

Inorganic elements have a major impact on the accumulation of secondary metabolites, but how do a variety of ecological factors affect inorganic elements in S. baicalensis? Comparing the data in Tables 3 and 4, we find that there is no relationship between correlation of some chemical compositions with inorganic element content in S. baicalensis and correlation between this chemical composition with this inorganic element content. To further study the relationship between inorganic elements in S. baicalensis and those in soil, the correlations among the inorganic elements of the root of $S$. baicalensis and the correlation between inorganic elements in the root of $S$. baicalensis and soil were analyzed.

The results of correlation analysis among inorganic elements of the root of $S$. baicalensis are shown in Table 5, and

Table 4 Correlation between inorganic elements and chemical composition of S. baicalensis ${ }^{\text {a) }}$

\begin{tabular}{|c|c|c|c|c|c|c|c|c|c|c|c|}
\hline & Element & $\mathrm{Ca}$ & $\mathrm{Cr}$ & $\mathrm{Cu}$ & $\mathrm{Fe}$ & $\mathrm{K}$ & $\mathrm{Mg}$ & $\mathrm{Mn}$ & $\mathrm{P}$ & $\mathrm{Sr}$ & $\mathrm{Zn}$ \\
\hline Component & $\begin{array}{c}\text { Significant } \\
\text { correlation number }\end{array}$ & 4 & 5 & 5 & 5 & 5 & 4 & 6 & 5 & 6 & 3 \\
\hline C 1 & 4 & -0.078 & $-0.232^{*}$ & 0.095 & 0.053 & $0.339^{* *}$ & $0.217^{*}$ & 0.132 & 0.147 & -0.052 & $0.224^{*}$ \\
\hline $\mathrm{C} 2$ & 1 & -0.025 & -0.105 & -0.048 & -0.108 & 0.171 & 0.118 & $-0.239^{*}$ & -0.063 & -0.163 & -0.124 \\
\hline C 3 & 3 & -0.006 & -0.165 & $-0.243^{*}$ & -0.091 & $0.205^{*}$ & 0.203 & -0.152 & -0.160 & -0.107 & $-0.256^{*}$ \\
\hline C 4-6 & 3 & 0.077 & $-0.321^{* *}$ & -0.169 & -0.165 & $0.273^{* *}$ & 0.105 & -0.161 & -0.200 & $-0.374^{* *}$ & -0.168 \\
\hline C 7 & 5 & -0.009 & $0.235^{*}$ & 0.033 & $0.306^{* *}$ & $-0.289^{* *}$ & 0.012 & 0.180 & $0.295^{* *}$ & $0.509^{* *}$ & 0.034 \\
\hline $\mathrm{C} 8$ & 2 & 0.016 & 0.034 & -0.176 & 0.159 & 0.032 & $0.213^{*}$ & 0.182 & $-0.208^{*}$ & 0.028 & -0.087 \\
\hline $\mathrm{C} 9$ & 7 & $-0.210^{*}$ & -0.187 & $-0.228^{*}$ & $-0.261^{*}$ & 0.029 & 0.046 & $-0.369^{* *}$ & $-0.219^{*}$ & $-0.272^{* *}$ & $-0.301^{* *}$ \\
\hline C 10 & 6 & $-0.209^{*}$ & $-0.217^{*}$ & $-0.282^{* * *}$ & -0.184 & $0.211^{*}$ & $0.249^{*}$ & -0.176 & $-0.221^{*}$ & -0.187 & -0.162 \\
\hline C 11 & 4 & -0.053 & -0.052 & $-0.250^{*}$ & -0.098 & -0.029 & 0.048 & $-0.215^{*}$ & $-0.210^{*}$ & $-0.226^{*}$ & -0.200 \\
\hline C 12 & 0 & -0.135 & -0.151 & -0.119 & -0.144 & -0.007 & 0.022 & -0.146 & -0.072 & -0.106 & -0.188 \\
\hline C 13 & 1 & -0.115 & -0.058 & $-0.222^{*}$ & -0.027 & -0.132 & -0.041 & -0.106 & -0.046 & 0.025 & -0.178 \\
\hline C 14 & 4 & $-0.216^{*}$ & $-0.205^{*}$ & -0.096 & -0.148 & -0.083 & 0.024 & $-0.278^{* *}$ & -0.004 & $-0.222^{*}$ & -0.125 \\
\hline C 16 & 2 & $0.312^{* *}$ & 0.054 & -0.063 & $0.216^{*}$ & 0.030 & 0.074 & 0.147 & -0.140 & 0.032 & 0.026 \\
\hline C 17 & 0 & 0.081 & -0.038 & -0.164 & 0.022 & 0.034 & -0.109 & -0.110 & -0.129 & -0.114 & -0.191 \\
\hline C 18 & 0 & 0.124 & 0.036 & 0.011 & 0.186 & 0.017 & 0.039 & 0.094 & 0.045 & -0.002 & 0.062 \\
\hline C 19 & 0 & 0.166 & 0.055 & 0.008 & 0.096 & 0.110 & 0.050 & -0.007 & 0.007 & -0.092 & 0.042 \\
\hline C 20 & 4 & 0.148 & $0.228^{*}$ & 0.066 & $0.361^{* *}$ & -0.029 & 0.048 & $0.325^{* *}$ & 0.084 & $0.271^{* *}$ & 0.117 \\
\hline C 21 & 0 & 0.029 & 0.129 & -0.018 & 0.089 & 0.073 & 0.120 & -0.010 & -0.013 & -0.057 & 0.007 \\
\hline
\end{tabular}

a) * shows significance at the level as $\alpha=0.05$; ** shows significance at the level as $\alpha=0.01$; C9 as baicalin, $\mathrm{C} 14$ as wogonoside, $\mathrm{C} 17$ as baicalein, $\mathrm{C} 18$ as wogonin. 
there are in total 45 correlation coefficients for every two elements among the 10 inorganic elements of S. baicalensis. Eighteen of these were significantly correlated, exceeding $1 / 3$ of the total number. The 10 inorganic elements, $\mathrm{Ca}, \mathrm{Cr}$, $\mathrm{Cu}, \mathrm{Fe}, \mathrm{K}, \mathrm{Mg}, \mathrm{Mn}, \mathrm{P}, \mathrm{Sr}$ and $\mathrm{Zn}$, are significantly correlated with other kinds of inorganic elements as with correlation frequencies of 4, 0, 2, 5, 2, 5, 5, 3, 5 and 7, respectively. Of these, $\mathrm{Ca}$ and $\mathrm{P}$ show negative correlations, suggesting antagonism between these two components; the other kinds of inorganic elements are positively correlated, suggesting that the majority of the absorption of inorganic elements may have a synergistic effect. Among them, $\mathrm{Zn}, \mathrm{Fe}, \mathrm{Mg}$, $\mathrm{Mn}$ and $\mathrm{Sr}$ of $S$. baicalensis are positively correlated with five or more other kinds of inorganic elements, suggesting that the absorption of these elements has a synergistic effect with a variety of inorganic elements.

\subsubsection{Correlation between inorganic elements in the root} of $S$. baicalensis and those in rhizosphere soil

The results of the correlation analysis between the root of $S$. baicalensis and inorganic elements of soil are shown in Table 6 , and only three medicinal materials, $\mathrm{Ca}, \mathrm{Cu}$ and $\mathrm{P}$, of the 10 kinds of inorganic elements of S. baicalensis are positively correlated with soil content, while the other seven elements of medicinal materials are not correlated. $\mathrm{Ca}, \mathrm{Cr}$,
$\mathrm{Cu}, \mathrm{Fe}, \mathrm{K}, \mathrm{Mg}, \mathrm{Mn}, \mathrm{P}, \mathrm{Sr}$ and $\mathrm{Zn}$ of $\mathrm{S}$. baicalensis are significantly correlated with the other $0,1,6,2,6,0,4,1,4$ and 5 inorganic elements in the soil, suggesting that several other inorganic elements have little or no influence on the accumulation of $\mathrm{Ca}$ and $\mathrm{Mg}$. Accumulation of $\mathrm{Cr}, \mathrm{Cu}, \mathrm{Fe}, \mathrm{K}$, $\mathrm{Mn}, \mathrm{P}, \mathrm{Sr}$ and $\mathrm{Zn}$ is influenced by the other inorganic elements in the soil, and accumulation of $\mathrm{Cu}, \mathrm{K}$ and $\mathrm{Zn}$ might be influenced by more inorganic elements. This reflects the fact that demand for different inorganic elements and absorption characteristics of $S$. baicalensis are different, suggesting that some inorganic elements of $S$. baicalensis are not only related with corresponding elements in the soil, but might be more related with other inorganic element components in the soil.

$\mathrm{Ca}, \mathrm{Cr}, \mathrm{Cu}, \mathrm{Fe}, \mathrm{K}, \mathrm{Mg}, \mathrm{Mn}, \mathrm{P}, \mathrm{Sr}$ and $\mathrm{Zn}$ in the soil are significantly correlated with the other inorganic elements of medicinal materials $1,4,3,3,1,5,3,3,4$ and 2. This suggests that $\mathrm{Cr}, \mathrm{Mg}$ and $\mathrm{Sr}$ in the soil have greater impacts on inorganic elements of $S$. baicalensis, among which soil $\mathrm{Mg}$ is significantly and negatively correlated with $\mathrm{Cr}, \mathrm{Fe}, \mathrm{Mn}$ and $\mathrm{Sr}$ of medicinal materials, while significantly and positively correlated with $\mathrm{K}$ in the medicinal materials, suggesting that $\mathrm{Mg}$ in the soil might promote $\mathrm{K}$ absorption by the root of S. baicalensis.

Table 5 Analysis of correlation among inorganic elements of the root of S. baicalensis $^{\text {a) }}$

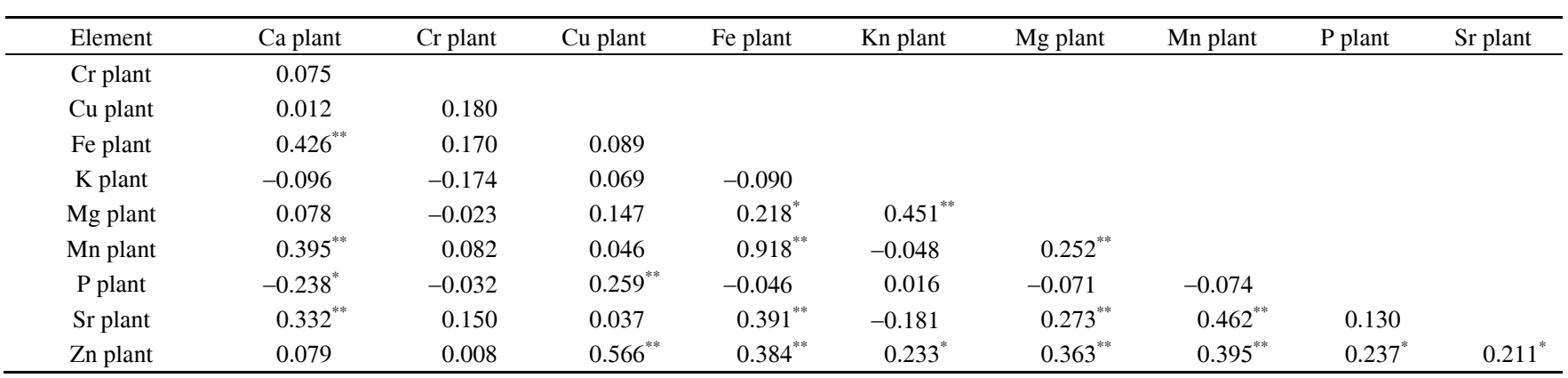

a) $*$ shows significance at the level as $\alpha=0.05$; ** shows significance at the level as $\alpha=0.01$.

Table 6 Correlation between inorganic elements in S. baicalensis and those in soil ${ }^{\text {a) }}$

\begin{tabular}{|c|c|c|c|c|c|c|c|c|c|c|}
\hline Element & Ca plant & Cr plant & $\mathrm{Cu}$ plant & Fe plant & $\mathrm{K}$ plant & Mg plant & Mn plant & P plant & Sr plant & Zn plant \\
\hline Ca soil & $0.227^{*}$ & -0.132 & -0.078 & -0.167 & 0.068 & -0.093 & $-0.309^{* *}$ & -0.067 & -0.123 & -0.131 \\
\hline Cr soil & -0.027 & -0.092 & $0.560^{* *}$ & -0.111 & $0.325^{* *}$ & 0.126 & -0.132 & 0.130 & $-0.236^{*}$ & $0.292^{* *}$ \\
\hline $\mathrm{Cu}$ soil & 0.051 & -0.146 & $0.356^{* *}$ & -0.067 & $0.405^{* *}$ & 0.107 & -0.083 & 0.063 & $-0.225^{*}$ & $0.189^{*}$ \\
\hline Fe soil & 0.017 & -0.094 & $0.470^{* *}$ & -0.046 & $0.363^{* *}$ & 0.130 & -0.054 & 0.121 & -0.169 & $0.253^{* * *}$ \\
\hline K soil & -0.168 & 0.007 & $0.452^{* *}$ & -0.102 & 0.020 & 0.048 & -0.037 & -0.014 & -0.093 & 0.154 \\
\hline Mg soil & -0.171 & $-0.259^{* *}$ & -0.077 & $-0.225^{*}$ & $0.295^{* *}$ & 0.149 & $-0.226^{*}$ & -0.075 & $-0.490^{* *}$ & -0.050 \\
\hline P soil & 0.129 & -0.026 & -0.073 & $0.369^{* * *}$ & 0.006 & 0.098 & $0.444^{* *}$ & $0.295^{* *}$ & $0.550^{* *}$ & 0.095 \\
\hline Sr soil & -0.029 & -0.064 & $0.594^{* *}$ & -0.072 & $0.190^{*}$ & 0.159 & -0.093 & $0.222^{*}$ & -0.078 & $0.306^{* *}$ \\
\hline Zn soil & -0.099 & -0.098 & $-0.209^{*}$ & 0.130 & 0.110 & -0.043 & $0.250^{* *}$ & 0.108 & 0.038 & 0.006 \\
\hline
\end{tabular}

a) * shows significance at the level as $\alpha=0.05 ; * *$ shows significance at the level as $\alpha=0.01$. 
3.2.3 Correlation between inorganic elements of S. baicalensis and ecological factors

As seen in Table 7, $\mathrm{P}$ and $\mathrm{Sr}$ in $S$. baicalensis are significantly and negatively correlated with altitude and annual average temperature, while significantly and positively correlated with longitude and latitude, suggesting that high temperature is not conducive for absorption of $\mathrm{P}$ and $\mathrm{Sr}$ by the root of $S$. baicalensis. Ecological factors such as climate do not affect absorption for other inorganic elements by $S$. baicalensis directly.

\subsection{Comprehensive effect of ecological factors on sec- ondary metabolites of $S$. baicalensis}

Secondary metabolites of $S$. baicalensis are a result of the comprehensive effect of various factors from both internal and external environment. To further analyze the compre-

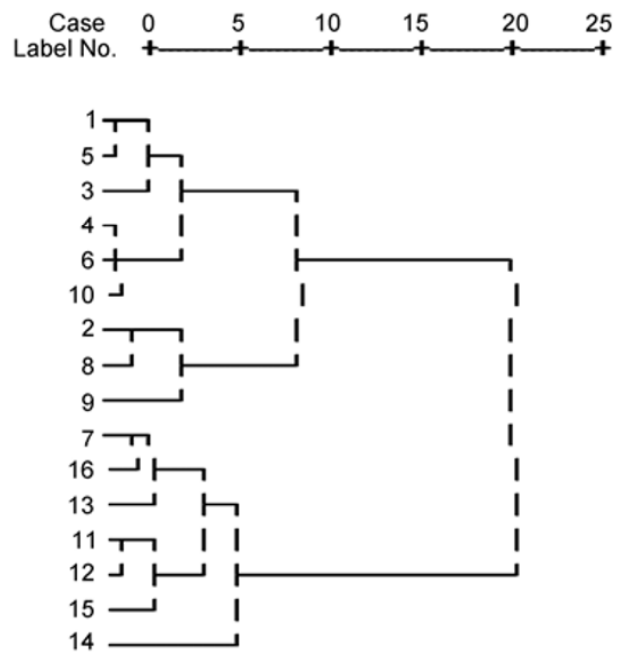

Figure 1 Dendrogram of chemical composition for $S$. baicalensis of different origins (associated method within groups). 1-16 represent separately: Huma, Heilongjiang Province; Ergun, Inner Mongolia; Duerbote, Heilongjiang Province; Baicheng, Jilin Province; Yanji, Jilin Province; Linxi, Inner Mongolia; Chifeng, Inner Mongolia; Chicheng, Hebei Province; Yanqing, Beijing; Paddock, Hebei Province; Wutai, Shanxi Province; Fenyang, Shaanxi Province; Yan'an, Shanxi Province; Heshui, Gansu Province; Taibai, Shaanxi Province; and Shanyang, Shaanxi Province. hensive effect of ecological factors on secondary metabolites of $S$. baicalensis. Euclidean distance was adopted and cluster analysis was carried out on $S$. baicalensis all over the world. An associated method was used within groups, based on 21 chemical compositions in S. baicalensis, and the result showed that $S$. baicalensis from different origins could be divided into two main categories (Figure 1). Among them, samples 1-10 (except 7) are clustered into one class while samples 11-16 and sample 7 are clustered into another class. When these sample plots are displayed on the map, it can be found that the first of these two groups is mainly distributed in the northeast regions of China, and the second group is mainly distributed in regions from the north to the northwest. The origin of these two groups does not cross geographically, but each group has a geographical continuity, indicating that ecological factors have comprehensive effects on the secondary metabolites of $S$. baicalensis.

\section{Discussion and conclusion}

\subsection{Effects of ecological factors and secondary metabo- lites of the root of $S$. baicalensis}

Under the conditions of heterogenic environments, accumulation of secondary metabolites in medicinal plants has different features [19]. The different contents or proportion of accumulated secondary metabolites of medicinal plants means that it is possible that the clinical therapeutic effects are not exactly the same even for the same kind of traditional Chinese medicine, leading to the differences in the clinical medicine quality of traditional Chinese medicines [20,21]. The relevant analysis aims at studying whether there is any interdependent relationship among these phenomena, discussing the relevant directions and conducting statistics and analyses of relevant degree towards the specific phenomena with interdependent relationships [22,23]. This study analyzed the correlation among secondary metabolites of the root of $S$. baicalensis and inorganic elements, and the ecological factors that might affect their content. It

Table 7 Correlation between inorganic elements of $S$. baicalensis and ecological factors ${ }^{\text {a) }}$

\begin{tabular}{cccccc}
\hline Element & Altitude $(\mathrm{m})$ & Latitude $\left({ }^{\circ} \mathrm{N}\right)$ & Longitude $\left({ }^{\circ} \mathrm{E}\right)$ & $\begin{array}{c}\text { Annual precipitation } \\
(\mathrm{mm})\end{array}$ & $\begin{array}{c}\text { Annual sunshine } \\
\text { duration }(\mathrm{h})\end{array}$ \\
\hline Ca plant & 0.022 & -0.120 & -0.210 & 0.115 & $\begin{array}{c}\text { Annual average } \\
\text { temperature }\left({ }^{\circ} \mathrm{C}\right)\end{array}$ \\
Cr plant & -0.374 & 0.437 & 0.341 & -0.374 & -0.186 \\
Cu plant & -0.274 & 0.326 & 0.255 & -0.165 & 0.219 \\
Fe plant & -0.232 & 0.376 & 0.260 & -0.122 & 0.401 \\
K plant & 0.183 & -0.366 & -0.328 & 0.315 & -0.002 \\
Mg plant & -0.031 & -0.120 & 0.021 & 0.236 & -0.220 \\
Mn plant & -0.253 & 0.342 & 0.319 & -0.079 & -0.269 \\
P plant & $-0.586^{*}$ & $0.669^{* *}$ & $0.662^{* *}$ & -0.131 & 0.027 \\
Sr plant & $-0.672^{* *}$ & $0.688^{* *}$ & $0.674^{* *}$ & -0.423 & 0.163 \\
Zn plant & -0.380 & 0.301 & 0.424 & -0.133 & -0.347 \\
\end{tabular}

a) * shows significance at the level as $\alpha=0.05$; ** shows significance at the level as $\alpha=0.01$. 
can be concluded from the correlation analysis of secondary metabolites of the root of $S$. baicalensis that different kinds of ecological factors have different extents of effects on different secondary metabolites of the root of S. baicalensis. The same kind of ecological factor may have different effects on different secondary metabolites. Most secondary metabolites have negative correlations with latitude and positive correlations with temperature, showing that high temperature is beneficial for accumulation of most secondary metabolites in the root of $S$. baicalensis. Different secondary metabolites are affected by different kinds of inorganic elements in the soil to different extents, where the inorganic elements including $\mathrm{Mg}, \mathrm{Mn}, \mathrm{Cr}$ and $\mathrm{Fe}$ in the soil all have relatively significant strong effect on secondary metabolites. Except for $\mathrm{Mg}$ and $\mathrm{Ca}$, too high a content of inorganic elements is unfavorable for accumulation of secondary metabolites of the root of S. baicalensis. Among the 21 components in the root of $S$. baicalensis, six components have no obvious correlation with inorganic elements. The correlation with inorganic elements of remaining components differs significantly while the frequencies of remarkable significant correlations with chemical components of different inorganic elements are approximately the same. Baicalin is the component that has the highest content in the root of S. baicalensis. The six ecological factors, soil and various kinds of inorganic elements in the medicinal materials have significant correlations with accumulation of baicalin, suggesting that multiple ecological factors have relatively significant effects on the accumulation of baicalin.

On the whole, different secondary metabolites in the root of $S$. baicalensis show significantly different responses towards different ecological factors, while various ecological factors have different effects and intensities on the accumulation of secondary metabolites in the root of S. baicalensis. Most secondary metabolites in the root of S. baicalensis have negative correlations with latitude and positive correlations with temperature. A similar phenomenon has also been found in many studies on Rhizoma atractylodis and Artemisia apiacea $[24,25]$. Research has shown that as a kind of phytoalexin, both synthesis and emission of secondary metabolites will increase under environmental stress [19], indicating that the relatively cool and cold zones are suitable for growth of $S$. baicalensis while high temperatures may lead to certain adversity stresses, consequently leading to synthesis of secondary metabolites.

\subsection{Effect of ecological factors on inorganic elements in the root of $S$. baicalensis}

Different kinds of inorganic elements have different functions inside the plant. Not only do inorganic elements affect root nutrition, physiological and metabolic activities of the plant, and promote plant growth, but they also constitute factors for active ingredients of medicinal plants. Therefore, inorganic elements affect formation and accumulation of chemical composition of plants [26-30]. To further observe the effect of inorganic elements on accumulation of secondary metabolites, this study analyzed the correlation between various ecological factors and accumulation of inorganic elements in the root of $S$. baicalensis. It can be concluded that except for the significantly negative correlation between $\mathrm{Ca}$ and $\mathrm{P}$ in the root of $\mathrm{S}$. baicalensis, there is positive correlation between the remaining inorganic elements, which shows that absorption of these inorganic elements might have synergistic reactions. In particular, absorption of $\mathrm{Zn}, \mathrm{Fe}, \mathrm{Mg}, \mathrm{Mn}$ and $\mathrm{Sr}$ has synergistic reactions with multiple inorganic elements. Among the 10 inorganic elements including $\mathrm{Ca}, \mathrm{Cr}, \mathrm{Cu}, \mathrm{Fe}, \mathrm{K}, \mathrm{Mg}, \mathrm{Mn}, \mathrm{P}, \mathrm{Sr}$ and $\mathrm{Zn}$ in the root of $S$. baicalensis, only three medicinal materials including $\mathrm{Ca}, \mathrm{Cu}$ and $\mathrm{P}$ are significantly positively correlated with contents in the soil while medicinal materials of the other seven elements are not significantly correlated with contents in the soil. On the contrary, this study showed that $\mathrm{Cr}, \mathrm{Cu}, \mathrm{Fe}, \mathrm{K}, \mathrm{Mn}, \mathrm{P}, \mathrm{Sr}$ and $\mathrm{Zn}$ in the root of S. baicalensis are significantly correlated with other inorganic elements in the soil. Furthermore, $\mathrm{Cu}, \mathrm{K}$ and $\mathrm{Zn}$ are correlated with many inorganic elements, indicating that their accumulation might be affected by more inorganic elements. Note that content of a certain inorganic element in the root of S. baicalensis might not only be correlated with the corresponding element content in the soil, but may also be closely correlated with contents of other inorganic elements in the soil. Different inorganic elements in the soil have different effects on inorganic elements in the roots of S. baicalensis, where $\mathrm{Cr}, \mathrm{Mg}$ and $\mathrm{Sr}$ have relatively significant effects on accumulation of inorganic elements in the root of S. baicalensis. Besides high temperatures, which are unfavorable for absorption of $\mathrm{P}$ and $\mathrm{Sr}$ by the root of S. baicalensis, this study showed that ecological factors have no direct effects on absorption of most inorganic elements by the root of $S$. baicalensis.

In recent years, it has been found that pesticide effects on traditional Chinese medicine have to do with the trace elements contained and the content proportion of various trace elements [31,32]. Cao et al. [24] noted that the active ingredient of Chinese medicine might be one or several organic elements or might be associated with trace elements, but is most likely formed by both. Other scholars have pointed out that there is complicated interaction among inorganic elements, which is reflected as a relationship that is equally important and irreplaceable [27,28]. For example, the $\mathrm{Cd}$ in plants can disturb metabolism of Fe, reduce effectiveness of $\mathrm{Fe}$ in plants [29] and block nutrient element transmission towards the leaves by disturbing the absorption and transfer of elements including $\mathrm{Mn}, \mathrm{Zn}$ and $\mathrm{Mg}$ by the plants through antagonism. This study has found a complicated correlation among the chemical composition in S. baicalensis, inorganic elements in S. baicalensis and inorganic elements in the soil. The three parts correlate with each other closely and form a complicated dynamic balance system, although they 
themselves are relatively independent systems. Therefore, it is difficult to obtain meaningful results by analyzing inorganic elements of Chinese medicine independently.

\subsection{Comprehensive effects of environment on the root of $S$. baicalensis and medicinal materials distribution of S. baicalensis geoherblism}

S. baicalensis has been widely distributed since ancient times. Shennong's Herbal Classic mentioned Zigui (Zigui, Hubei Province) and Yuanju (Heze, Shandong Province); Annotated Shennong's Herbal mentioned Pengcheng and Yuzhou (both located in modern Jiangsu Province); Newly Revised Canon of Materia Medica mentioned Yizou (Yichang, Hubei Province), Lizhou (Fu County, Shaanxi Province), and Jingzhou (Jing County, Gansu Province); Supplement to Invaluable Prescriptions for Ready Reference: Originating Places of Medicine mentioned Ningzhou (modern Ning County, Gansu Province ), and Jingzhou (modern Jing County, Gansu Province); Classified Materia Medica mentioned Luzhou (modern Changzhi, Shaanxi Province) and that Yaozhou (modern Yao County, Shaanxi Province) abounded in S. baicalensis. Commentaries on the Illustrations recorded that "Neighboring counties of Sichuan, Eastern Yellow River and Shaanxi all abound in it". An Illustrated Book on Plants recorded that "Southern Yunnan abounds in it" and Medicine Production Differentiation recorded that "the areas in Shanxi, Zhili and Rehe abound in it". In modern times, the main production areas of $S$. baicalensis have shifted northward and are currently mainly concentrated in three areas including Northern, Northwestern and Northeastern China. When it comes to the genuine production area of S. baicalensis, Newly Revised Canon of Materia Medica recorded that "the plant growing in Yizhou, Lizhou and Jingzhou is better", where Yizhou refers to Yichang, modern Hubei Province, Lizhou refers to modern Fu County, Shaanxi Province and Jingzhou is Jing County, Gansu Province $[33,34]$. Since the beginning of this century, some scholars have claimed that $S$. baicalensis produced in Chengde, Hebei Province is a genuine medicinal material [2], while Gansu, Shanxi, Hebei and Shandong provinces have all shown to be genuine production areas for $S$. baicalensis. This shows that more research is needed to confirm the genuine production area of $S$. baicalensis. This study has found that contents of 21 chemical compositions, including baicalin, in $S$. baicalensis in areas with low latitude are higher than at higher latitude on the whole. The cluster analysis based on 21 components has roughly divided $S$. baicalensis from 16 production areas into two major categories, where the 21 components have higher contents in S. baicalensis in Chifeng, Inner Mongolia; Wutai, Shanxi Province; Fenyang, Shanxi Province; Yan'an, Shaanxi Province; Heshui, Gansu Province; and Taibai, Shaanxi Province. Other production areas have lower contents. This has revealed the reason for different records for genuine production areas of $S$. baicalensis by ancient people from the other side, i.e., geoherblism of $S$. baicalensis is not limited to a small area. The area stretching from Chifeng, Inner Mongolia to Taibai, Shaanxi Province is suitable for accumulation of secondary metabolites of $S$. baicalensis, and is suitable for growth and production of $S$. baicalensis. In other words, this area has the potential to become a genuine production area for S. baicalensis as long as S. baicalensis is produced with enough output and processed by reasonable means.

This work was supported by the National Natural Science Foundation of China (81130070, 81072989) and the National Key Technology Research and Development Program of China (2012BAI29B02).

1 Xiao X H. Ecological and biological investigation on quality variation of traditional Chinese medicinal materials. Chin Med Herb, 1989, 20: $42-46$

2 Hu S L. Genuine Medicinal Materials of China. Harbin: Science and Technological Press of Heilongjiang, 1989

3 Huang L Q, Zhang R X. Biological investigation on "genuine medicinal materials". J Chin Pharm, 1997, 9: 563-566

4 Huang L Q, Guo L P, Hu J, et al. Molecular mechanism and heritage background of genuineness of Chinese medicine. J Chin Pharm, 2008, 33: 2303-2308

5 Ferreyra M L F, Rius S P, Casati P. Flavonoids: Biosynthesis, biological functions, and biotechnological applications. Front Plant Sci, 2012, doi: 10.3389/fpls.2012.00222

6 Hartmann T. Plant-derived secondary metabolites as defensive chemicals in herbivorous insects: A case study in chemical ecology. Planta, 2004, 219: 1-4

7 Heldt H W, Piechulla B. Plant Biochemistry. 4th ed. London: Academic Press, 2010. 400

8 Kliebenstein D J. Making new molecules-evolution of structures for novel metabolites in plants. Curr Opin Plant Biol, 2013, doi: 10.1016/j.pbi.2012.12.004

9 Wink M, Mohamed G I A. Evolution of chemical defense traits in the Leguminosae: Mapping of distribution patterns of secondary metabolites on a molecular phylogeny inferred from nucleotide sequences of the rbcL gene. Biochem Syst Ecol, 2003, 31: 897-917

10 Ncube B, Finnie J F, Van Staden J. Quality from the field: The impact of environmental factors as quality determinants in medicinal plants. S Afr J Bot, 2012, 82: 11-20

11 Xiao P G. Newly Revised Chinese Medicine History. Beijing: Chemistry Industry Press, 2002. 862

12 Yang Q, Bai Y, Chen Q L, et al. Current status of Sbaicalensis resources and research on sustainable utilization. Lishizhen Med Mater Med Res, 2006, 17: 1159-1160

13 Su S, He C M, Li L C, et al. Genetic characterization and phytochemical analysis of wild and cultivated populations of Sbaicalensis. Chem Biodivers, 2008, 5: 1353-1363

14 Guo L P, Huang L Q, Jiang Y X, et al. Selection of dominant climate factors and climate suitability regionalization of components of rhizoma atractylodis oil. J Chin Pharm, 2007, 32: 888-893

15 Guo L P, Huang L Q, Lv D M. Construction and application of space analysis database of genuine medicinal materials of Chinese medicine based on 3S technology. J Chin Pharm, 2007, 32: 1821-1824

16 Zobayed S M A, Afreen F, Kozai T. Temperature stress can alter the photosynthetic efficiency and secondary metabolite concentrations in St. John's wort. Plant Physiol Biochem, 2005, 43: 977-984

17 Zaidi F, Voirin B, Jay M, et al. Free flavonoid aglycones from leaves of Mentha pulegium and Mentha suaveolens (Labiatae). Phytochemistry, 1998, 48: 991-994

18 Rivas-Ubach A, Sardans J, Pérez-Trujillo M, et al. Strong relation- 
ship between elemental stoichiometry and metabolome in plants. Proc Natl Acad Sci USA, 2012, 109: 4181-4186

19 Huang L Q, Guo L P. Effects of accumulation of secondary metabolites on formation of genuine medicinal materials under environmental press. J Chin Pharm, 2007, 32: 277-280

20 Guo L P, Liu J Y, Ji L, et al. Feature analysis of components of volatile oil of genuine medicinal materials of Atractylis lancea. J Chin Pharm, 2002, 27: 814-819

21 Guo L P, Huang L Q, Hua Y L, et al. Research from phenotype plasticity, ecotype and chemical type of medicinal type. Resource Sci, 2008, 30: 744-753

22 Wang L Y, Meng F Y, Zhang W S, et al. Research on correlation between medicinal materials of Aconitum vilmorianum Kom raw and inorganic elements of soil. J Beijing Univ Chin Med, 2005, 28: 68-71

23 Yin H B, Zhang N, Kang T G. Research on correlation between medicinal materials of Dioscorea nipponica and inorganic elements of soil. Chin J Clin Lab Sci, 2011, 17: 137-141

24 Zeng Y, Guo L P, Chen B D, et al. Effects of different temperatures on growth of Atractylis lancea and components of volatile oil. World Sci Tech-Mod Trad Chin Med, 2010, 12: 773-778

25 Liu C C, Wang Y C, Ouyang F, et al. Research on cultivation conditions for synthetizing arteannuin from hairy roots of Artemisia apiacea. Bot Gazette, 1998, 40: 831-835

26 Cao Z Q, Sun Z M, Sun A Z. Trace Elements and Traditional Chinese Medicine. Beijing: China Press of Traditional Chinese Medicine,
1993. $155-156$

27 Guo M. Research on Correlation between Inorganic Elements and Quality of Cortex Moutan. Nanjing: Nanjing Agricultural University, 2008

28 Zhao M Q, Lv J R, Guo L P, et al. The effects of inorganic elements in soil on content of inorganic elements and baicalin in Sbaicalensis. Chin J Clin Lab Sci, 2010, 16: 103-106

29 Zhao M Q, Lv J R, Yang G, et al. The effects of inorganic elements in soil on content of inorganic elements in Radix Paeoniae Rubrathe and content of peoniflorin. Chin J Clin Lab Sci, 2009, 15: 38-42

30 Zhou C Z, Li Y, Yang C S, et al. Genuine medicinal materials of Asarum sieboldi Mig. and trace elements. Chin Med Herb, 2000, 4: 54-57

31 Wang L S. Research on Content of Trace Elements in Panax and Rhizosphere Soil. Jilin: Jilin Agricultural University, 2008

32 Dong S F, Liu J, Dong H B, et al. Research on measurement of metal element content and cluster analysis for 11 kinds of Chinese medicine including Radix Salviae Miltiorrhizae. Spectrosc Spec Anal, 2006, 26: 2150-2153

33 Kong W W. Evaluation Research on Quality of the Root of Sbaicalensis and Its Ecological Suitability. Changchun: Jilin Agricultural University, 2008

34 Li Z. Research on Bencaological Study of Sbaicalensis and Distribution and Transition of Genuine Production Areas. Beijing: China Academy of Traditional Chinese Medicine, 2010

Open Access This article is distributed under the terms of the Creative Commons Attribution License which permits any use, distribution, and reproduction in any medium, provided the original author(s) and source are credited. 